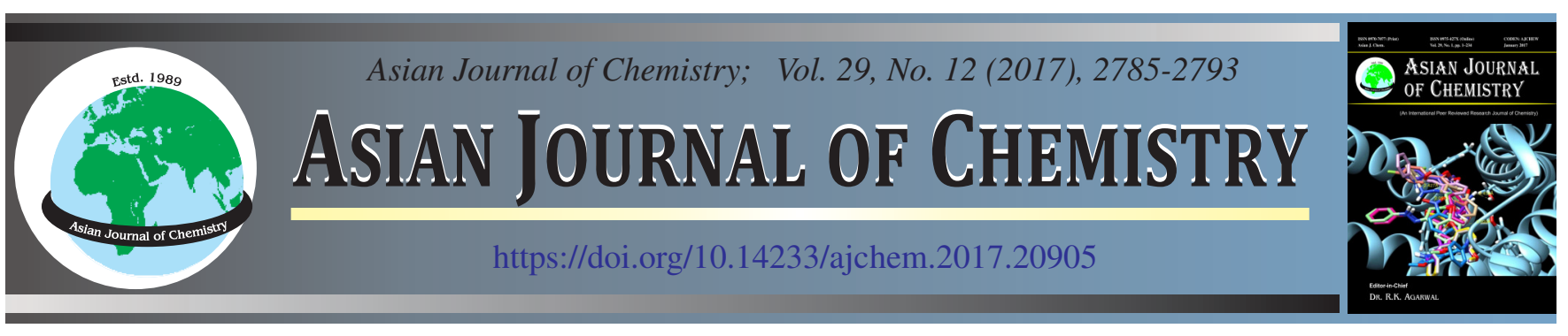

\title{
Application of Quality by Design for Development and Validation of RP-HPLC Method for Lercanidipine Hydrochloride
}

\author{
Chandrakant Bonde, Smita Bonde and Jineet Kumar Gawad*
}

SVKM's NMIMS School of Pharmacy and Technology Management, Shirpur Campus, Shirpur-425 405, India

*Corresponding author: E-mail: jineetkumar.gawad@nmims.edu

\begin{abstract}
Current research deals with the development of accurate, precise and robust analytical liquid chromatographic method for lercanidipine hydrochloride by application of quality by design $(\mathrm{QbD})$. The key objective of research was to monitor the factors affecting the quality of analysis and also to identify the conditions where an adequate separation in minimal analysis duration could be achieved within a robust region. Basic process parameters which have the most impact on method performance were defined as proportion of acetonitrile in the mobile phase, $\mathrm{pH}$ of the aqueous phase and the flow rate. Quality by design (QbD) approach provided quantitative process knowledge which can be used to identify the HPLC instrument parameter settings that provided optimum chromatographic performance. The method optimization was accomplished using Fusion $\mathrm{AE}^{\mathrm{TM}}$ software (SMatrix Corporation, Eureka, CA) in 2 phases. In Phase 1, rapid screening was done to reduce the number of independent variables followed by phase II where the method was optimized using a DOE approach. Response surface design was implemented for experimental robustness testing and the method is validated to verify the adequacy of selected ideal chromatographic conditions: the analytical column of phenomenex C18 (250 mm $\times 4.6 \mathrm{~mm}, 5 \mu \mathrm{m}$ particle size $)$, mobile phase consist of acetonitrile-aqueous phase (10 mM phosphate buffer, $\mathrm{pH}$ adjusted to 4.5, (Gradient, organic phase 82 to $95 \% \mathrm{v} / \mathrm{v}$ ), pump flow rate 1.2 $\mathrm{mL} / \mathrm{min}$, and wavelength of detection $236 \mathrm{~nm}$. The quality by design $(\mathrm{QbD})$ based method development helped in better understanding of the overall method capabilities and limitations and ensured a greater chance of effective method validation.
\end{abstract}

Keywords: Quality by design, Lercanidipine hydrochloride, Liquid chromatography.

\section{INTRODUCTION}

Quality by Design (QbD) is a concept first coined by wellknown quality expert Joseph M. Juran in numerous publications, most notably Juran on QbD [1]. While QbD standards have been utilized to boost process quality in each industry, and especially the vehicle industry, they have most as of late been embraced by the U.S. Food and Drug Administration (FDA) as a vehicle for the change of how drugs are found, created, and industrially produced. Since first started by the U.S. FDA in its "Pharmaceutical cGMPs for the 21st century, QbD has turned into an essential idea for the pharmaceutical business that is additionally characterized in the International Conference on Harmonization ( $\mathrm{ICH}$ ) direction on pharmaceutical improvement as "an efficient way to deal with advancement that starts with predefined destinations and underscores item and process understanding and process control, in view of sound science and quality hazard administration [2]. The logical understanding picked up amid the strategy improvement process can be used to devise technique control components and to deal with the risk identified.
Liquid chromatographic method development can be a long and time-consuming procedure because can be repeated many times throughout a drug development timeline [3,4]. Methods are commonly developed using one-factor-at-a-time (OFAT) approach in which one variable is changed sequentially until a suitable method is produced. This way may create an adequate method but provides a limited understanding of method capabilities and method robustness. Therefore, $\mathrm{QbD}$ approach is used that evaluates a number of stationary phases, $\mathrm{pH}$ ranges and organic modifiers which help in optimization of analytical method.

Lercanidipine hydrochloride, a calcium channel blocker, which is chemically 2[(3,3-diphenylpropyl)methylamino]-1,1dimethylethylmethyl-2,6-dimethyl-4-(3-nitrophenyl)-1,4 dihydro pyridine-3,5-dicarboxylate (Fig. 1). Its molecular formula is $\mathrm{C}_{36} \mathrm{H}_{41} \mathrm{~N}_{3} \mathrm{O}_{6} \cdot \mathrm{HCl}$ and molecular weight $648.19 \mathrm{~g} /$ mol $[5,6]$. Lercanidipine hydrochloride is used for treatment of angina pectoris and hypertension [7]. It inhibits cellular influx of calcium leading to the maintenance of the plateau phase of the action potential [8,9]. Considering that lercanidipine is a novel drug, few analytical methods for its determination have been described. Among them is a capillary electrophoresis 


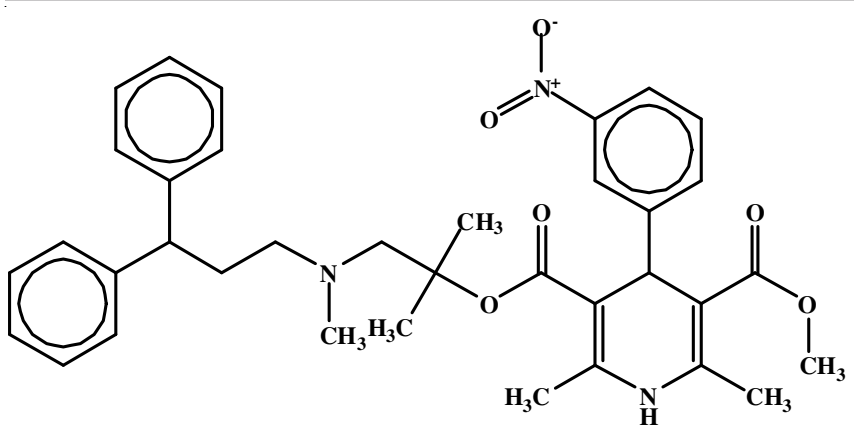

Fig. 1. Structure of lercanidipine

for pure drug [10,11], HPLC-UV detection for clinical pharmacokinetics study [12] and HPLC method using both UV and electrochemical (amperometric type) detection in order to determine lercanidipine in commercial tablets [5].

To our best of knowledge and after an exhaustive survey of the literature, there is no evidence of the establishment of a quantitative relationship between the variables using explicit statistical analysis for the analysis of lercanidipine hydrochloride. Consequently, implementation of quality by design (QbD) approach for better understanding of variables is the challenge of pharmaceutical analysis. In the present work, analytical RP-HPLC method was developed by the application of $\mathrm{QbD}$ for lercanidipine hydrochloride and optimized method was validated as per ICH guidelines.

\section{EXPERIMENTAL}

Lercanidipine hydrochloride, an active pharmaceutical ingredient (API) was obtained from Torrent Research Centre, Ahmedabad, India. HPLC grade acetonitrile and methanol were purchased from Merck, India. Potassium dihydrogen orthophosphate and AR grade orthophosphoric acid were purchased from Merck, India. HPLC grade water was obtained from milli-Q water purification system (Millipore, Milford, USA). Hydrochloric acid and hydrogen peroxide were purchased from Merck, India whereas sodium hydroxide pellets were purchased from RFCL limited SQ grade.

A HPLC (Perkin Elmer; Model: Lambda 25) consisting of P.E. Binary LC Pump 200B/250 (Perkin Elmer; Model: series 200); Vacuum degasser; UV-VIS detector (Perkin Elmer, Model: series 200); C8 and C18 reverse phase columns (Phenomenex: $250 \mathrm{~mm} \times 4.60 \mathrm{~mm}$, particle size $5 \mu \mathrm{m}$ ) and a sample injector system (Rheodyne) with a $20 \mu \mathrm{L}$ sample loop and total chrome navigator software (version V 6.3.1) on computer operated with Windows 2003 Professional. Vacuum filtration assembly (Orchid Scientifics, Model: JVP01); ultrasonicator (Oscar, Model: Microclean 103); weighing balance (SHIMADZU AUX - 120); A double beam UV-visible spectrophotometer with $1 \mathrm{~cm}$ path length (PerkinElmer); Digital $\mathrm{pH}$ meter (Labindia $\mathrm{Pico}+$ ) and QbD software fusion AETM (S-Matrix Corporation, Eureka, CA).

Selection of analytical wavelength: For RP-HPLC method analytical wavelength was determined from UV spectra of lercanidipine hydrochloride recorded by using UV-visible spectrophotometer. Stock solution $(1000 \mu \mathrm{g} / \mathrm{mL})$ of the drug was prepared in acetonitrile and further diluted to get $10 \mu \mathrm{g} / \mathrm{mL}$ of solution with the methanol. The solution was scanned in the UV range between 200 to $400 \mathrm{~nm}$ against acetonitrile as blank. The ultra- violet absorption spectrum was obtained as shown in Fig. 2 and the maximum absorption peak $\left(\lambda_{\max }\right)$ is found at $236 \mathrm{~nm}$. Therefore, the detection wavelength of detector was set at this wavelength for further analysis.

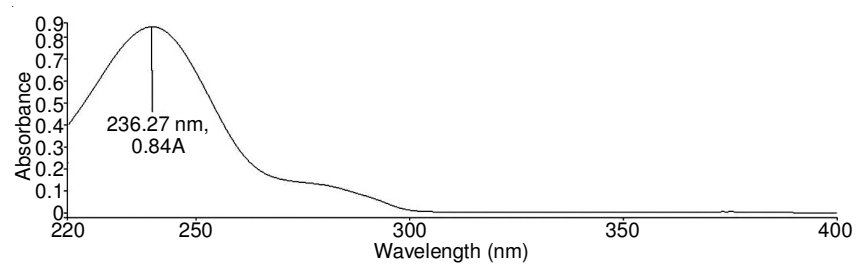

Fig. 2. UV spectra of lercanidipine hydrochloride in methanol

Preparation of mobile phase: $10 \mathrm{mM}$ solution of potassium dihydrogen phosphate $\left(\mathrm{KH}_{2} \mathrm{PO}_{4}\right)$ buffer was prepared by dissolving $0.68 \mathrm{~g}$ of $\mathrm{KH}_{2} \mathrm{PO}_{4}$ in $500 \mathrm{~mL}$ of HPLC grade water. Then it was vacuum filtered through $0.45 \mu$ Millipore PVDF filter and $\mathrm{pH}$ was adjusted with ortho-phosphoric acid or $\mathrm{KOH}$ and kept it as A1 line. Acetonitrile was kept as B1 line and methanol was kept as B2 line. All the solvents were sonicated using ultrasonicator for 15 min before using as mobile phase.

Preparation of standard stock solution and sample solution: The mixture of acetonitrile and water $(8: 2)$ was used as diluent. Accurately weighed and transferred $10 \mathrm{mg}$ of lercanidipine hydrochloride into a $10 \mathrm{~mL}$ volumetric flask, a small amount of diluent was added and sonicated to dissolve the material completely. Diluted to volume with diluent and mixed well. Transferred $1 \mathrm{~mL}$ of the above standard stock solution in a $10 \mathrm{~mL}$ volumetric flask, diluted to volume with diluent and mixed well to get the final concentration of $100 \mathrm{ug} / \mathrm{mL}$.

Method development by QbD approach: The method development studies described here were performed using an automated integrated system consisting of fusion AE method development software, total chrome navigator software for chromatography data system and Perkin Elmer HPLC system. Fusion AE method development software (S-Matrix Corporation, Eureka, CA) is a quality by design based LC method development software with build in robustness metrics. Fusion AE builds experiments, analyzes data and presents the results as visual and numerical method predictions. Using fusion AE method development software HPLC method development was done in two phases.

Phase 1-Rapid screening: The most important parameters that influence the retention behaviour of the analytes are column, organic solvent content and $\mathrm{pH}$ of the buffer. Therefore, the first phase of the method development involved the screening of the three main parameters of the HPLC, primarily the column, buffer $\mathrm{pH}$ and organic phase and other parameters were kept constant like column temperature, pump flow rate, injection volume, wavelength, sample concentration, etc. Parameters are shown in the Tables 1 and 2. An experimental design was generated within fusion AE method development software including randomization and replicate samples. The design generated covered the entire knowledge space defined by constants and variables entered during the experimental setup and used partial factorial statistics to obtain the maximum amount of information with the least number of experimental runs.

The experimental design was then exported to Perkin Elmer HPLC instrument. The experimental design was run and data 


\begin{tabular}{ll}
\hline \multicolumn{1}{c}{ PHASE 1 EXPERIMENT VARIABLES } \\
\hline \multicolumn{1}{c}{ Parameters } & \multicolumn{1}{c}{ Description of parameters } \\
\hline \multicolumn{1}{c}{ MH } & \multicolumn{1}{c}{$\begin{array}{c}\mathrm{C}_{8}, \mathrm{C}_{18} \\
\text { Mobile phase }\end{array}$} \\
\multicolumn{1}{c}{ PHASE 1 EXPERIMENT CONSTANTS } \\
\hline \multicolumn{1}{c}{ Acetonitrile: Buffer; Methanol: Buffer } \\
\hline
\end{tabular}

processed on the chromatographic system and results were imported back to fusion AE software.

The experimental results were evaluated using goals in automated optimizer wizard to identify the most promising column, $\mathrm{pH}$, and mobile phase to be used as the final method conditions. From the analyzed data, software predicted the optimum LC method after modelling all significant effects- linear, interaction and complex on each critical method performance characteristics and obtained the multiple response interactions and overlay graph. Software searched the LC method that meets all the performance goals simultaneously and the best overall answer was reported along with predicted results for an experimental run. These optimized conditions were used for the next stage- method optimization.

Phase 2-Method optimization: Phase 2 experiments used the column, $\mathrm{pH}$ and organic phase composition results from phase 1 plus additional variables with tighter ranges to determine the optimum LC method. The experimental design was created using pump flow rate and sample concentration as final optimization variables in fusion $\mathrm{AE}$ method development software and exported it to Perkin Elmer HPLC instrument. These variables are shown in Tables 3 and 4.

Lercanidipine hydrochloride method optimization-multiple response interactions: The experimental design was executed and data processed on the chromatographic system and results were imported back into fusion AE. Then the data were analyzed for final method optimization and obtained multiple response

TABLE-3

PHASE 2 EXPERIMENT VARIABLES

\begin{tabular}{ll}
\hline Parameters & Description of parameters \\
\hline Pump flow rate $(\mathrm{mL} / \mathrm{min})$ & $1.0,1.2,1.4$ \\
Sample concentration $(\mu \mathrm{g} / \mathrm{mL})$ & $40,60,80,100,120$ \\
\hline
\end{tabular}

TABLE-4

PHASE 2 EXPERIMENT CONSTANTS

\begin{tabular}{ll}
\hline Constant name & Constant value \\
\hline Column type & $\mathrm{C}_{18}$ \\
Mobile phase & Acetonitrile: Buffer $\left(\mathrm{KH}_{2} \mathrm{PO}_{4}\right)$ \\
$\mathrm{pH}$ & 4.492 \\
Injection volume & $20 \mu \mathrm{L}$ \\
Oven temperature & Ambient \\
Equilibration time & $5.0 \mathrm{~min}$ \\
Initial hold time & $2.0 \mathrm{~min}$ \\
Initial hold \% organic & $82.5 \mathrm{~mL}$ \\
Gradient & $82.5 \mathrm{to} 95$ \\
Gradient time & $10.0 \mathrm{~min}$ \\
Final hold time & $2.0 \mathrm{~min}$ \\
Final hold \% organic & $95.0 \mathrm{~mL}$ \\
Ramp up to wash time & $2.0 \mathrm{~min}$ \\
Column wash time & $10.0 \mathrm{~min}$ \\
Column wash \% organic & $99.0 \mathrm{~mL}$ \\
Ramp down from wash time & $2.0 \mathrm{~min}$ \\
Re-equilibration time & $5.0 \mathrm{~min}$ \\
Re-equilibration \% organic & $95.0 \mathrm{~mL}$ \\
\hline
\end{tabular}

interactions graphs. Here fusion AE applied a combination of Monte Carlo simulation and process capability statistics to evaluate method robustness without running additional experiments.

Lercanidipine hydrochloride method optimization-final optimized results: The overlay graph was generated using various critical chromatographic responses. The overlay graph showed the QbD design space where the method meets the mean performance goals and robustness criteria. Utilizing automated optimizer wizard the LC method performance goals and robustness goals were defined and ranked in order of importance. Software searched the LC method that meets all the performance goals simultaneously. The best overall answer (final optimized method condition) was obtained along with predicted response results for this method.

Specificity: The specificity of the developed analytical method for lercanidipine hydrochloride was determined in the presence of its degradation products. Relative retention time and response factor was calculated for each impurity.

Linearity and range: Linear calibration plot was obtained over the calibration ranges tested, i.e. 25 to $750 \mu \mathrm{g} / \mathrm{mL}$. The peak area versus concentration data was performed by least squares linear regression analysis. Linearity was reported as the correlation coefficients and the slope of the regression line.

Precision: The precision was evaluated by carrying out six replicates of three concentration levels from the entire range. The percentage of relative standard deviation (R.S.D.) of six assay values was calculated.

Accuracy: For drug, recovery studies were carried out by applying the method to a drug sample to which known amounts of lercanidipine hydrochloride corresponding to 80, 100 and $120 \%$ had been added (standard addition method). Accuracy of the method was evaluated by spiking the drug at three different concentrations of samples. The percent recovery of added drug was calculated from a calibration curve.

Robustness: Robustness was determined by analysis of samples under purposely altered conditions like, flow rate \pm 0.2 unit, mobile phase buffer solution $\mathrm{pH} \pm 0.2$ unit, detection wavelength \pm 2 unit. Robustness of the method was determine at a concentration level of $100 \mu \mathrm{g} / \mathrm{mL}$. One factor was changed 
at one time to estimate the effect. The effect on retention time and peak parameters was studied.

Ruggedness: The ruggedness of the optimized analytical method was evaluated in terms of degree of reproducibility of test results was obtained by the analysis of same samples under a variety of conditions such by performing inter and intraday studies.

\section{Forced degradation study}

Acid induced degradation: $4 \mathrm{~mL}$ of $1 \mathrm{~N} \mathrm{HCl}$ was taken in a round bottom flask and $1 \mathrm{~mL}(1000 \mu \mathrm{g} / \mathrm{mL})$ of lercanidipine hydrochloride was added and subjected to reflux at $80^{\circ} \mathrm{C}$ for $1 \mathrm{~h}$. Then $4 \mathrm{~mL}$ of $1 \mathrm{~N} \mathrm{NaOH}$ was added to neutralize the solution and allowed to attain room temperature and made up the volume up to $10 \mathrm{~mL}$ with diluent. Filtered through teflon membrane $0.45 \mu$ filter and injected the solution into HPLC column.

Base induced degradation: $4 \mathrm{~mL}$ of $1 \mathrm{~N} \mathrm{NaOH}$ was taken in a round bottom flask and to this was added $1 \mathrm{~mL}(1000 \mu \mathrm{g} /$ $\mathrm{mL}$ ) of lercanidipine hydrochloride and subjected to reflux at $80{ }^{\circ} \mathrm{C}$ for $1 \mathrm{~h}$. Then $4 \mathrm{~mL}$ of $1 \mathrm{~N} \mathrm{HCl}$ was added to neutralize the solution and allowed to attain room temperature and made the volume up to $10 \mathrm{~mL}$ with diluent. Filtered through teflon membrane $0.45 \mu$ filter and injected the solution into HPLC column.

Hydrogen peroxide induced degradation: $4 \mathrm{~mL}$ of 10 $\% \mathrm{H}_{2} \mathrm{O}_{2}$ was taken in a round bottom flask and to this $1 \mathrm{~mL}$ $(1000 \mu \mathrm{g} / \mathrm{mL})$ of lercanidipine hydrochloride was added and subjected to reflux at $80^{\circ} \mathrm{C}$ for $1 \mathrm{~h}$ and then made up the volume up to $10 \mathrm{~mL}$ with diluent. Filtered through teflon membrane $0.45 \mu$ filter and injected the solution into HPLC column.

Thermal degradation: $10 \mathrm{~mL}(1000 \mu \mathrm{g} / \mathrm{mL})$ stock solution of lercanidipine hydrochloride was taken in a round bottom flask and subjected to reflux at $100{ }^{\circ} \mathrm{C}$ for $1 \mathrm{~h} .1 \mathrm{~mL}$ of solution was collected and made the volume up to $10 \mathrm{~mL}$ with diluent and injected the solution [13-15].

\section{RESULTS AND DISCUSSION}

Phase 1-Rapid screening: In the initial phase, organic solvent (acetonitrile or methanol) was screened varying from $80-82.5 \%$, over an aqueous phase $\mathrm{pH}$ range from 3 to 7 . Experimental design matrix generated for rapid screening and chromatographic responses obtained are shown in Table-5. From the results, it can be observed that retention time of lercanidipine hydrochloride is strongly affected by $\mathrm{pH}$.

The responses were analyzed graphically where multiple response interactions graph (Fig. 3a-c) showed the combined effects of two variables i.e. proportion of organic solvent and $\mathrm{pH}$ of mobile phase on key chromatographic responses like peak retention time, tailing factor and theoretical plates. In these graphs, darker shade represents the magnitude of interaction and the curvature indicates the type of interaction.

The overlay graph for C18 column with acetonitrile as organic mobile phase is illustrated in Fig. 4, which highlights the experimental region where the mean performance goals were obtained. The white region of the overlay plot shows the design space, which defines the robust region of the method where the results were within the designed criteria. By changing the

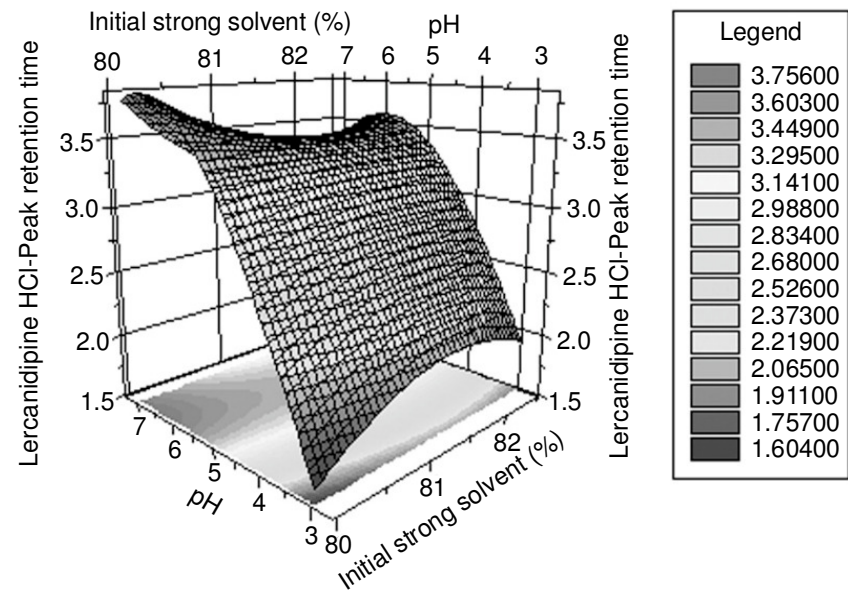

Fig. 3a. Response surface graph showing effect of solvent and $\mathrm{pH}$ on peak retention time

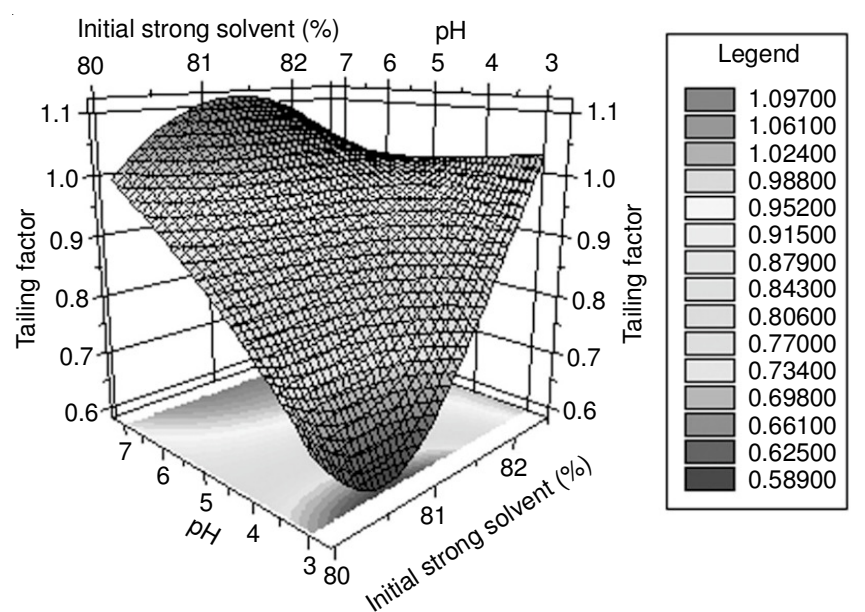

Fig. 3b. Response surface graph showing effect of solvent and $\mathrm{pH}$ on tailing factor

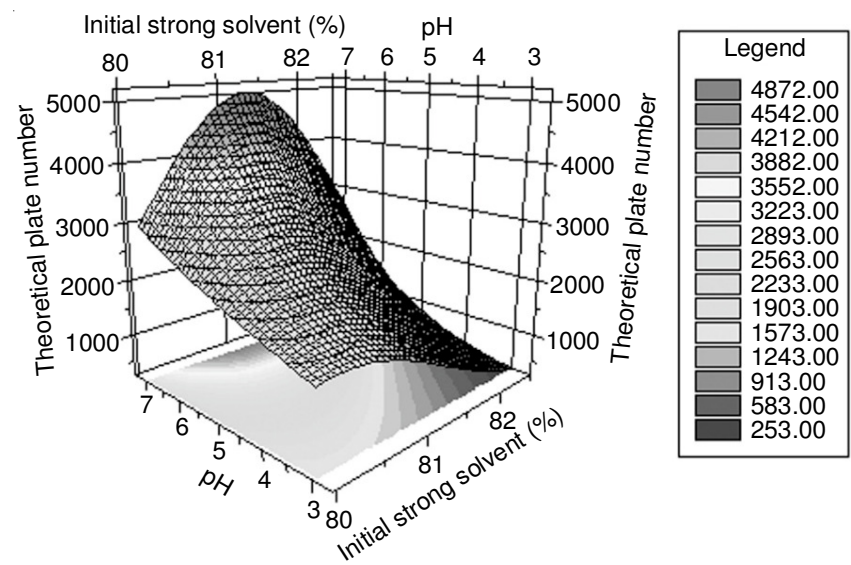

Fig. 3c. Response surface graph showing effect of solvent and $\mathrm{pH}$ on theoretical plate number

factors on each axis, the design space can be explored in detail and method robustness can be fully understood.

Phase 2-Method optimization: Multiple response interactions graph showed (Fig. 5a-c) the combined effects of two variables i.e. sample concentration and pump flow rate on key chromatographic responses such as peak retention time, tailing factor and theoretical plates. 
TABLE-5

EXPERIMENT DESIGN MATRIX AND RESPONSES OBTAINED

\begin{tabular}{|c|c|c|c|c|c|c|c|}
\hline Run No. & $\begin{array}{c}\text { Strong solvent } \\
\text { type }\end{array}$ & $\begin{array}{c}\text { Initial \% strong } \\
\text { solvent }(\mathrm{mL})\end{array}$ & $\mathrm{pH}$ & Column type & $\begin{array}{l}\text { Retention } \\
\text { time (min) }\end{array}$ & Tailing factor & $\begin{array}{c}\text { Theoretical } \\
\text { plate number }\end{array}$ \\
\hline 1 & Acetonitrile & 82.5 & 3 & $\mathrm{C} 8$ & 1.828 & 1.022 & 243.97 \\
\hline 2 & Acetonitrile & 80.0 & 3 & $\mathrm{C} 18$ & 1.46 & 1.503 & 580.6 \\
\hline 3 & Acetonitrile & 80.0 & 3 & $\mathrm{C} 18$ & 1.495 & 1.495 & 654.01 \\
\hline Condition Column-3 & Acetonitrile & 81.9 & 4 & $\mathrm{C} 8$ & & & \\
\hline Condition Column-4 & Acetonitrile & 81.9 & 4 & $\mathrm{C} 18$ & & & \\
\hline 4 & Acetonitrile & 81.9 & 4 & $\mathrm{C} 18$ & 3.447 & 2.137 & 439.82 \\
\hline 5 & Acetonitrile & 80.6 & 4 & $\mathrm{C} 8$ & 2.907 & 0.629 & $1,839.97$ \\
\hline Condition Column-5 & Acetonitrile & 81.3 & 5 & $\mathrm{C} 8$ & & & \\
\hline Condition Column-6 & Acetonitrile & 81.3 & 5 & $\mathrm{C} 18$ & & & \\
\hline 6 & Acetonitrile & 81.3 & 5 & $\mathrm{C} 18$ & 4.918 & 1.034 & $5,502.34$ \\
\hline 7 & Acetonitrile & 82.5 & 5 & $\mathrm{C} 18$ & 4.375 & 1.07 & $4,298.74$ \\
\hline 8 & Acetonitrile & 81.3 & 5 & $\mathrm{C} 8$ & 3.412 & 0.995 & $2,750.69$ \\
\hline 9 & Acetonitrile & 81.3 & 5 & $\mathrm{C} 18$ & 4.921 & 1.029 & $5,498.62$ \\
\hline 10 & Acetonitrile & 81.3 & 5 & $\mathrm{C} 8$ & 3.339 & 0.994 & $2,716.59$ \\
\hline Condition Column-7 & Acetonitrile & 81.3 & 6 & $\mathrm{C} 8$ & & & \\
\hline Condition Column-8 & Acetonitrile & 81.3 & 6 & $\mathrm{C} 18$ & & & \\
\hline 11 & Acetonitrile & 81.3 & 6 & $\mathrm{C} 8$ & 3.543 & 0.996 & $3,030.73$ \\
\hline 12 & Acetonitrile & 81.3 & 6 & $\mathrm{C} 18$ & 5.458 & 1.086 & $6,072.98$ \\
\hline Condition Column-9 & Acetonitrile & 81.3 & 7 & $\mathrm{C} 8$ & & & \\
\hline Condition Column-10 & Acetonitrile & 81.3 & 7 & $\mathrm{C} 18$ & & & \\
\hline 13 & Acetonitrile & 81.3 & 7 & $\mathrm{C} 18$ & 5.283 & 1.126 & $5,297.75$ \\
\hline 14 & Acetonitrile & 82.5 & 7 & $\mathrm{C} 8$ & 3.315 & 0.987 & $2,642.47$ \\
\hline 15 & Acetonitrile & 82.5 & 7 & $\mathrm{C} 8$ & 3.319 & 0.978 & $2,715.64$ \\
\hline 16 & Acetonitrile & 80.0 & 7 & $\mathrm{C} 8$ & 3.748 & 0.99 & $3,133.8$ \\
\hline Condition Column-11 & Methanol & 82.5 & 3 & $\mathrm{C} 8$ & & & \\
\hline Condition Column-12 & Methanol & 82.5 & 3 & $\mathrm{C} 18$ & & & \\
\hline 17 & Methanol & 82.5 & 3 & $\mathrm{C} 18$ & 6.59 & 0.712 & 562.36 \\
\hline 18 & Methanol & 80.0 & 3 & $\mathrm{C} 8$ & 4.117 & 0.689 & 779.86 \\
\hline 19 & Methanol & 80.0 & 3 & $\mathrm{C} 8$ & 4.119 & 0.701 & 776.45 \\
\hline Condition Column-13 & Methanol & 80.6 & 4 & $\mathrm{C} 8$ & & & \\
\hline Condition Column-14 & Methanol & 80.6 & 4 & C18 & & & \\
\hline 20 & Methanol & 80.6 & 4 & $\mathrm{C} 18$ & 6.432 & 1.193 & $1,842.7$ \\
\hline 21 & Methanol & 81.9 & 4 & $\mathrm{C} 8$ & 4.365 & 0.825 & $1,826.45$ \\
\hline Condition Column-15 & Methanol & 81.3 & 5 & $\mathrm{C} 8$ & & & \\
\hline Condition Column-16 & Methanol & 81.3 & 5 & $\mathrm{C} 18$ & & & \\
\hline 22 & Methanol & 81.3 & 5 & $\mathrm{C} 8$ & 5.156 & 0.982 & $3,346.37$ \\
\hline 23 & Methanol & 81.3 & 5 & $\mathrm{C} 18$ & 7.222 & 1.064 & $8,355.44$ \\
\hline 24 & Methanol & 81.3 & 5 & $\mathrm{C} 8$ & 5.185 & 0.947 & $3,465.42$ \\
\hline 25 & Methanol & 82.5 & 5 & $\mathrm{C} 8$ & 4.233 & 0.979 & $2,374.2$ \\
\hline 26 & Methanol & 81.3 & 5 & C18 & 7.252 & 1.056 & $8,139.05$ \\
\hline Condition Column-17 & Methanol & 80.0 & 7 & $\mathrm{C} 8$ & & & \\
\hline Condition Column-18 & Methanol & 80.0 & 7 & $\mathrm{C} 18$ & & & \\
\hline 27 & Methanol & 80.0 & 7 & $\mathrm{C} 18$ & 8.082 & 1.024 & $11,424.38$ \\
\hline 28 & Methanol & 81.3 & 7 & $\mathrm{C} 8$ & 5.113 & 0.835 & $3,570.1$ \\
\hline 29 & Methanol & 80.0 & 7 & $\mathrm{C} 8$ & 5.213 & 0.832 & $3,758.02$ \\
\hline 30 & Methanol & 82.5 & 7 & $\mathrm{C} 18$ & 6.633 & 1.017 & $6,492.02$ \\
\hline Condition Column-19 & Methanol & 82.5 & 7 & $\mathrm{C} 8$ & & & \\
\hline Condition Column-20 & Methanol & 82.5 & 7 & $\mathrm{C} 18$ & & & \\
\hline
\end{tabular}

Pump flow rate is an important parameter affecting both factors, average retention and selectivity in gradient elution. As shown in Fig. 5a, linear relationship was found between retention times and pump flow rates. Whereas no effect of sample concentration on retention time was observed. This is evident from Fig. 5b showing the effect of pump flow rate on tailing factor. High peak tailing was noted with increasing sample concentration. This may be because of overload of the column with the analyte. $\Delta \varphi$ is the range of percentage of the strong solvent (\% B) in gradient analysis (final \% B - initial $\% \mathrm{~B})$ and is typically defined during initial method development. tG is gradient time, which in conjunction with $\Delta \varphi$ defines the gradient slope. Increasing $\mathrm{tG}$ often increases the overall resolution of complex samples. For efficient gradient optimization the use of software simulation programs is very useful, since the predictions on the effects of gradient factors are not always intuitive [16].

The overlay graph for pump flow rate with sample concentration is shown in Fig. 6, which highlights the experimental region where the mean performance goals were obtained. The white region of the overlay plot shows the design space, which defines the robust region of the method where the results were within the designed criteria. By altering the factors on each axis, the design space can be studied in detail and method robustness 


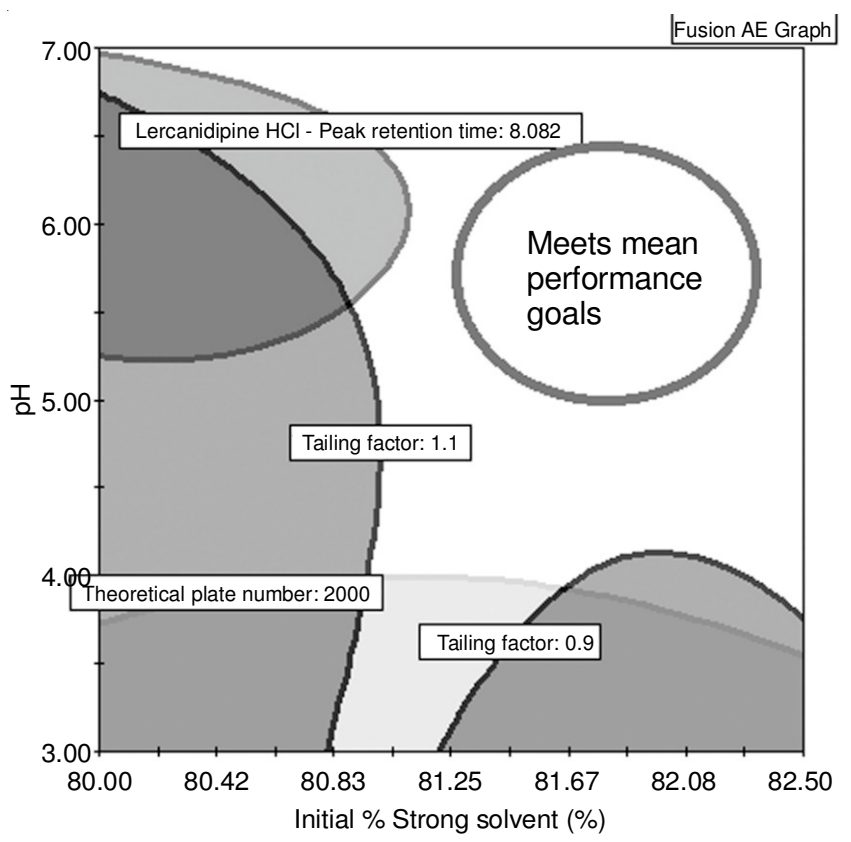

Fig. 4. Overlay graph for rapid screening of initial variables
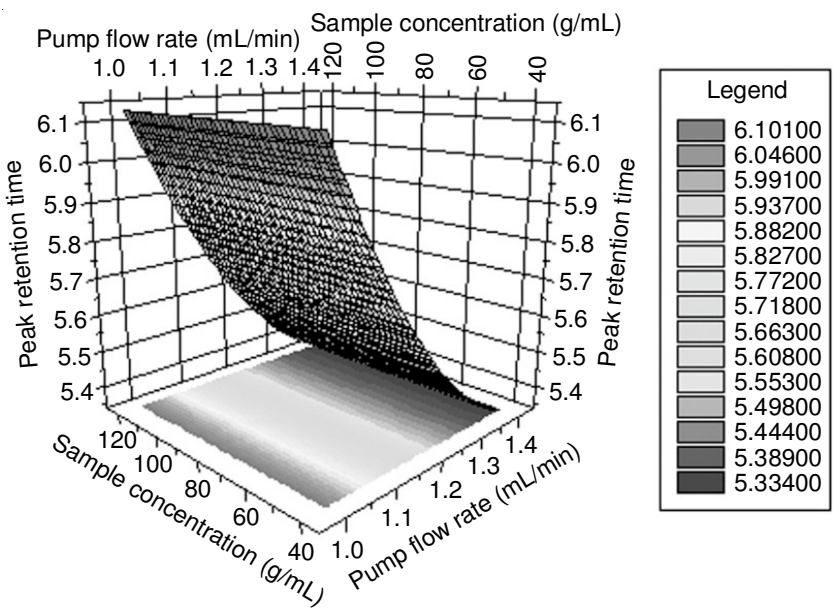

Fig. 5a. Response surface graph showing effect of pump flow rate and sample concentration on peak retention time

Pump flow rate $(\mathrm{mL} / \mathrm{min})$ Sample concentration $(\mathrm{g} / \mathrm{mL})$
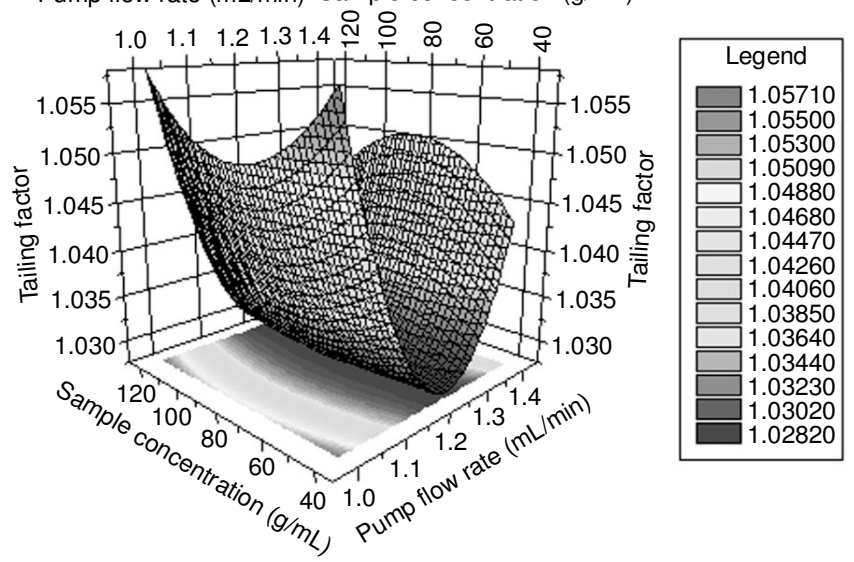

Fig. 5b. Response surface graph showing effect of pump flow rate and sample concentration on tailing factor

can be fully understood. The sample chromatograph obtained by using optimized conditions is shown in Fig. 7.

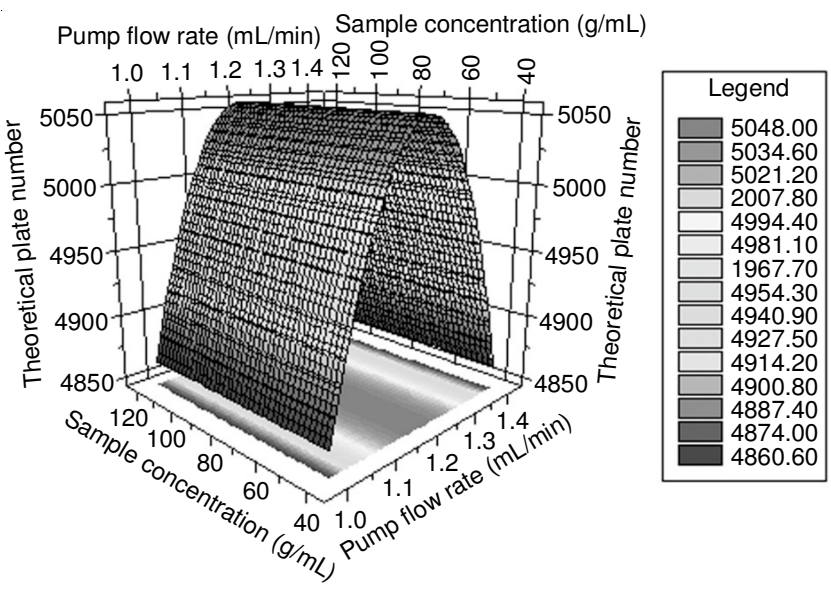

Fig. 5c. Response surface graph showing effect of pump flow rate and sample concentration on theoretical plate number

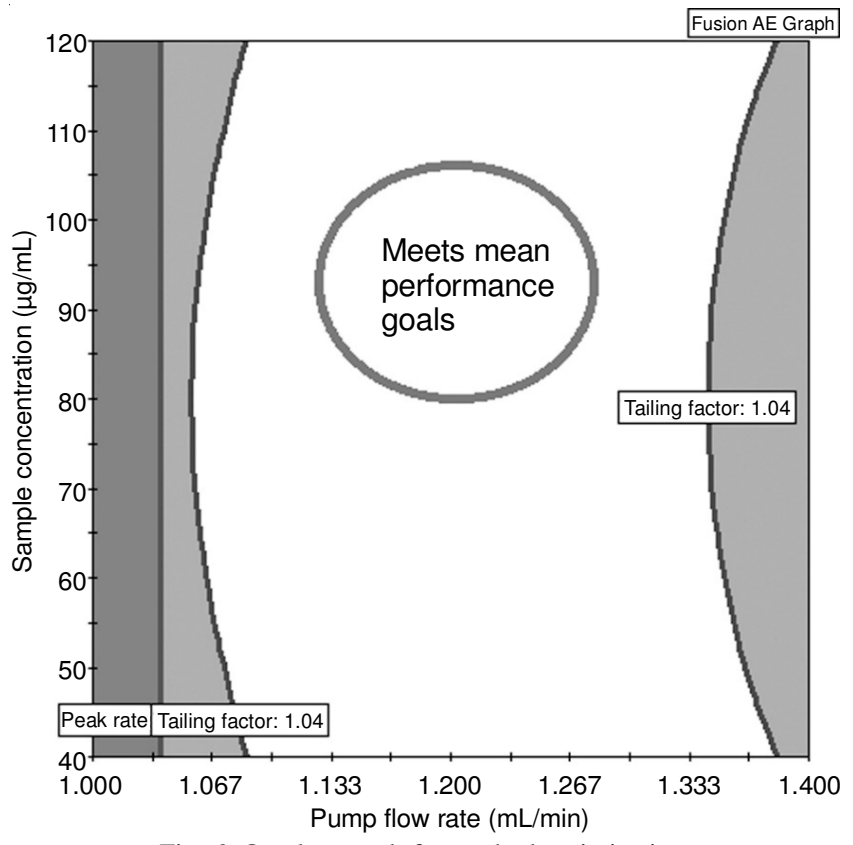

Fig. 6. Overlay graph for method optimization

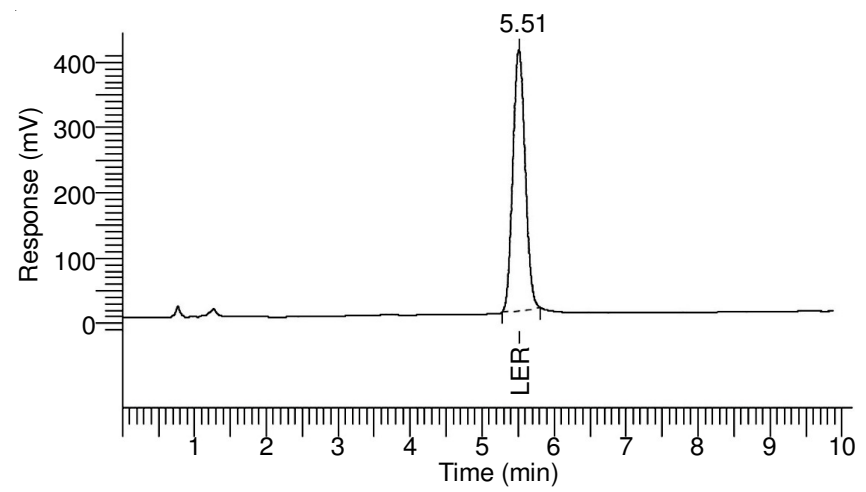

Fig. 7. Chromatograph of optimized method for analysis of lercanidipine hydrochloride

\section{Analytical method validation}

Specificity: The chromatograms obtained for the blank and the sample solution are shown in Figs. 8 and 9, respectively. From the chromatogram of blank, it was found that there is no interference of blank peak at the retention time of the drug peak therefore the method is specific. 


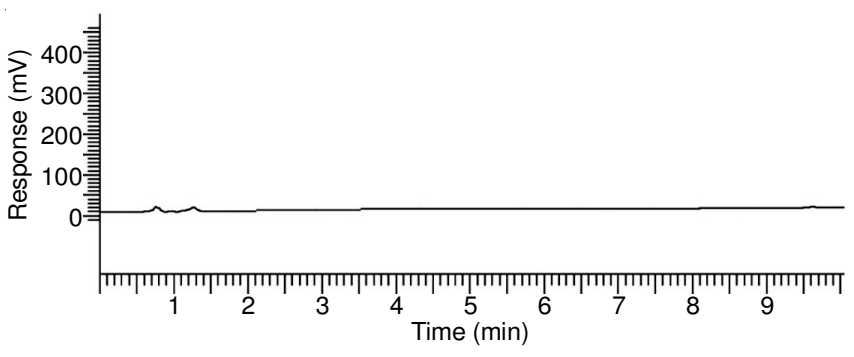

Fig. 8. Chromatogram of blank

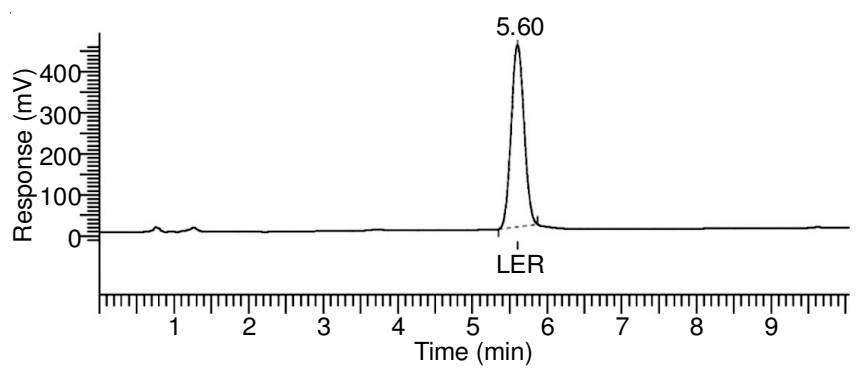

Fig. 9. Chromatogram of lercanidipine hydrochloride

Linearity: Table $6 \mathrm{a}$ and $6 \mathrm{~b}$ show the results of linearity, which reveals great linear calibration in the range of 40 to 120 $\mu \mathrm{g} / \mathrm{mL}$. X is the concentration of lercanidipine hydrochloride and $r$ is correlation coefficient. The high $r$ value was indicative for a good fitting of the model or good linearity. The representative chromatogram is shown in Fig. 10 and the linearity graph is shown in Fig. 11.

TABLE-6a

LINEAR REGRESSION DATA FOR CALIBRATION CURVES OF LERCANIDIPINE HYDROCHLORIDE

\begin{tabular}{ll}
\hline Parameters & Results \\
\hline$\lambda_{\max }(\mathrm{nm})$ & 236 \\
Linearity range & $40-120 \mu \mathrm{g} / \mathrm{mL}$ \\
Regression equation $(\mathrm{y}=\mathrm{mx}+\mathrm{b})$ & $\mathrm{y}=43134 \mathrm{x}+212650$ \\
Correlation coefficient $\left(\mathrm{r}^{2}\right)$ & 0.9989 \\
\hline
\end{tabular}

TABLE-6b

LINEAR REGRESSION DATA FOR CALIBRATION CURVES OF LERCANIDIPINE HYDROCHLORIDE

\begin{tabular}{ccccc}
\hline $\begin{array}{c}\text { Conc. } \\
(\mu \mathrm{g} / \mathrm{mL})\end{array}$ & Area 1 & Area 2 & Area 3 & Mean \\
\hline 40 & 1975173.34 & 1971700.26 & 1922643.24 & 1956505.613 \\
60 & 2733345.81 & 2767054.24 & 2796182.77 & 2765527.607 \\
80 & 3653302.19 & 3670248.54 & 3606827.28 & 3643459.337 \\
100 & 4616986.66 & 4598744.61 & 4576453.18 & 4597394.82 \\
120 & 5357487.47 & 5310622.64 & 5393813.76 & 5353974.623 \\
\hline
\end{tabular}

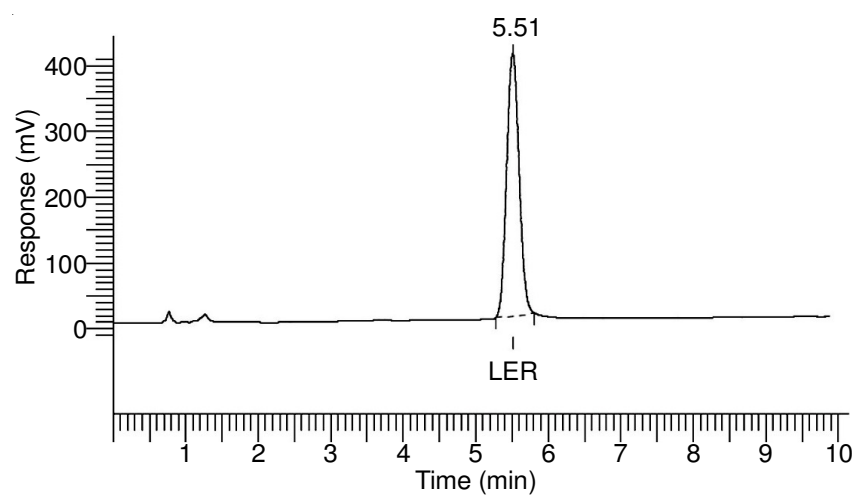

Fig. 10. Chromatogram of lercanidipine hydrochloride

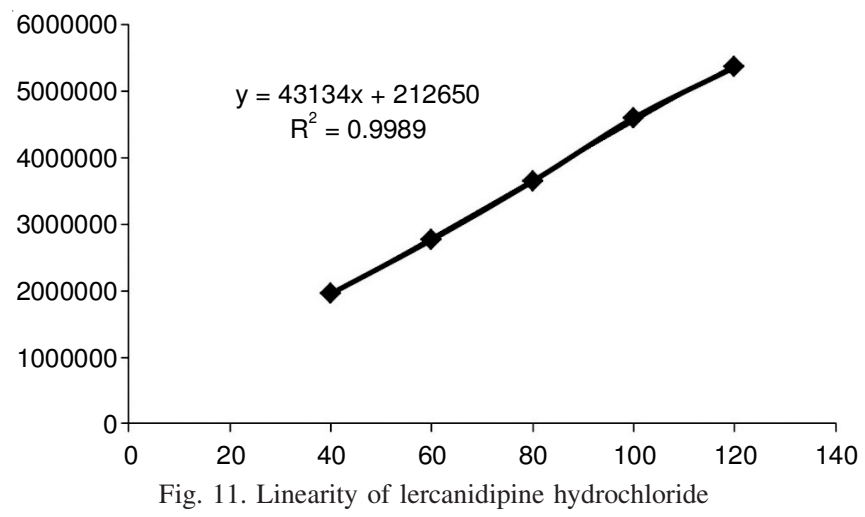

Precision: The percent relative standard deviation (\% RSD) for inter and intraday precision for lercanidipine hydrochloride is shown in Table-7. These results indicate that the developed method is precise.

Accuracy (recovery studies): This experiment was carried out at three different levels in which the sample stock solution was spiked along with the standard drug solution containing 80,100 , and $120 \%$ of sample solution of drug i.e. lercanidipine hydrochloride. Percent recovery is shown in Table-8. These results reveal that any small change in the drug concentration in the solution could be accurately determined by the proposed method.

Robustness: The results from the assay of the test solutions were not affected by altering the conditions and were in accordance with the results for the original conditions. The value of assay determined for the same sample under original conditions and robustness conditions indicates that the developed method is robust for effect of changed wavelength, $\mathrm{pH}$ and flow rate. All the evaluations were based on the system suitability parameters such as retention time, tailing factor and theoretical plates. Results are presented in Table-9.

\begin{tabular}{|c|c|c|c|c|c|c|c|}
\hline \multicolumn{8}{|c|}{$\begin{array}{c}\text { TABLE-7 } \\
\text { PRECISION DATA OF LERCANIDIPINE HYDROCHLORIDE }\end{array}$} \\
\hline & Conc. $(\mu \mathrm{g} / \mathrm{mL})$ & Area 1 & Area 2 & Area 3 & Mean & SD & RSD (\%) \\
\hline \multirow{3}{*}{ Inter-day } & 40 & 1926651.10 & 1925124.27 & 1913413.64 & 1921729.67 & 7242.240 & 0.38 \\
\hline & 60 & 2774952.45 & 2782943.86 & 2794534.27 & 2784143.57 & 9845.878 & 0.35 \\
\hline & 80 & 3650346.68 & 3684246.73 & 3695462.81 & 3676685.47 & 23489.285 & 0.64 \\
\hline \multirow{3}{*}{ Intra-day } & 40 & 1976482.67 & 1985643.65 & 1954679.84 & 1972268.72 & 15906.21 & 0.81 \\
\hline & 60 & 2789431.28 & 2775613.58 & 2789763.71 & 2784936.19 & 8075.328 & 0.29 \\
\hline & 80 & 3659783.22 & 3651346.62 & 3656792.79 & 3655974.21 & 4277.454 & 0.12 \\
\hline
\end{tabular}


TABLE-8

ACCURACY DATA OF LERCANIDIPINE HYDROCHLORIDE

\begin{tabular}{|c|c|c|c|c|c|c|c|}
\hline Spike level (\%) & Conc. $(\mu \mathrm{g} / \mathrm{mL})$ & Amount added & Amount found & Recovered (\%) & $\begin{array}{c}\text { Recovery }(\%) \\
\text { Mean }\end{array}$ & Recovery SD & $\begin{array}{c}\text { Recovery (\%) } \\
\text { RSD }\end{array}$ \\
\hline \multirow{3}{*}{80} & 50 & 40 & 89.79 & 99.48 & \multirow{3}{*}{99.04} & \multirow{3}{*}{0.44} & \multirow{3}{*}{0.45} \\
\hline & 50 & 40 & 89.44 & 98.59 & & & \\
\hline & 50 & 40 & 89.62 & 99.04 & & & \\
\hline \multirow{3}{*}{100} & 50 & 50 & 99.56 & 99.11 & \multirow{3}{*}{99.09} & \multirow{3}{*}{0.48} & \multirow{3}{*}{0.48} \\
\hline & 50 & 50 & 99.30 & 98.61 & & & \\
\hline & 50 & 50 & 99.78 & 99.56 & & & \\
\hline \multirow{3}{*}{120} & 50 & 60 & 109.77 & 99.62 & \multirow{3}{*}{99.62} & \multirow{3}{*}{0.72} & \multirow{3}{*}{0.72} \\
\hline & 50 & 60 & 110.21 & 100.34 & & & \\
\hline & 50 & 60 & 109.34 & 98.90 & & & \\
\hline
\end{tabular}

TABLE-9

ROBUSTNESS DATA OF LERCANIDIPINE HYDROCHLORIDE

\begin{tabular}{|c|c|c|c|c|}
\hline S. No. & Change in parameter & Parameter as per method & Change parameter to & $\operatorname{RSD}(\%)$ \\
\hline \multirow{2}{*}{1} & \multirow{2}{*}{ Flow rate $( \pm 0.2 \mathrm{~mL} / \mathrm{min})$} & \multirow{2}{*}{$1.2 \mathrm{~mL} / \mathrm{min}$} & $1.0 \mathrm{~mL} / \mathrm{min}$ & 0.93 \\
\hline & & & $1.4 \mathrm{~mL} / \mathrm{min}$ & 0.43 \\
\hline \multirow{2}{*}{2} & \multirow{2}{*}{ Change in wavelength $( \pm 2 \mathrm{~nm})$} & \multirow{2}{*}{$236 \mathrm{~nm}$} & $234 \mathrm{~nm}$ & 0.82 \\
\hline & & & $238 \mathrm{~nm}$ & 0.95 \\
\hline \multirow{2}{*}{3} & \multirow{2}{*}{$\mathrm{pH}( \pm 0.2)$} & \multirow{2}{*}{4.492} & 4.292 & 1.06 \\
\hline & & & 4.692 & 1.24 \\
\hline
\end{tabular}

Ruggedness: The ruggedness study proved the reliability of the test method for different days and different analysts in chromatographic condition. Thus, the ruggedness of the method is well established $[17,18]$. Results are given in Table-10.

\begin{tabular}{|c|c|c|c|}
\hline \multicolumn{4}{|c|}{$\begin{array}{c}\text { TABLE-10 } \\
\text { RUGGEDNESS DATA OF LERCANIDIPINE HYDROCHLORIDE }\end{array}$} \\
\hline \multicolumn{2}{|c|}{ Day 1 , Analyst 1} & \multicolumn{2}{|c|}{ Day 8, Analyst 2} \\
\hline Samples & Area & Samples & Area \\
\hline 1 & 4594348.61 & 1 & 4618237.87 \\
\hline 2 & 4605682.19 & 2 & 4602348.42 \\
\hline 3 & 4535186.64 & 3 & 4535467.86 \\
\hline 4 & 4594568.53 & 4 & 4543908.97 \\
\hline 5 & 4534677.32 & 5 & 4524389.35 \\
\hline 6 & 4613446.41 & 6 & 4587764.75 \\
\hline Mean & 4579651.62 & Mean & 4568686.20 \\
\hline S.D & 35378.01 & S.D & 39069.39 \\
\hline$\%$ RSD & 0.77 & $\%$ RSD & 0.86 \\
\hline
\end{tabular}

Forced degradation study: Forced degradation was performed for lercanidipine hydrochloride in acidic, alkaline, oxidation and thermal conditions. All the degradant peaks were well resolved along with lercanidipine hydrochloride, during force degradation study. Figs. 12-15 show the chromatograms of acid, base, hydrogen peroxide and heat induced degradation in lercanidipine hydrochloride, respectively. Degradation behaviour of lercanidipine hydrochloride under different stress conditions is depicted in Table-11. Maximum degradation (18.34\%) was observed in thermal degradation studies, suggesting that lercanidipine hydrochloride is more sensitive to the heat in comparison with other stress conditions.

Analytical method development: Factors that affect the quality of chromatogram mainly depend on the nature of analyte. The change in retention time with $\mathrm{pH}$ can be attributed to basic nature of the drug. As lercanidipine hydrochloride is a weak base, it is protonated at low $\mathrm{pH}$ and retention is increased. Whereas it is deprotonated at increasing $\mathrm{pH}$ and retention is



Fig. 12. Chromatogram of acid induced degradation

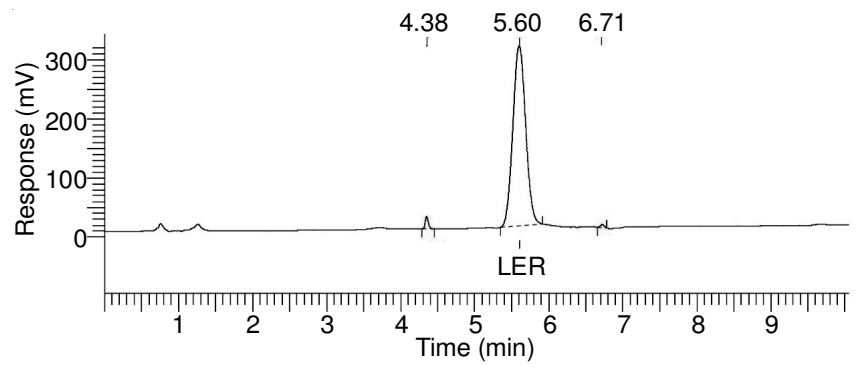

Fig. 13. Chromatogram of base induced degradation



Fig. 14. Chromatogram of hydrogen peroxide induced degradation

decreased. It was also pointed out that good peak shape is obtained when the $\mathrm{pH}$ is lowered. In chromatographic determination, good peak shape is important for more accurate quantitation and longer usable column lifetime. Excellent peak shape can be defined by tailing factor of 1 and narrow peak width. 


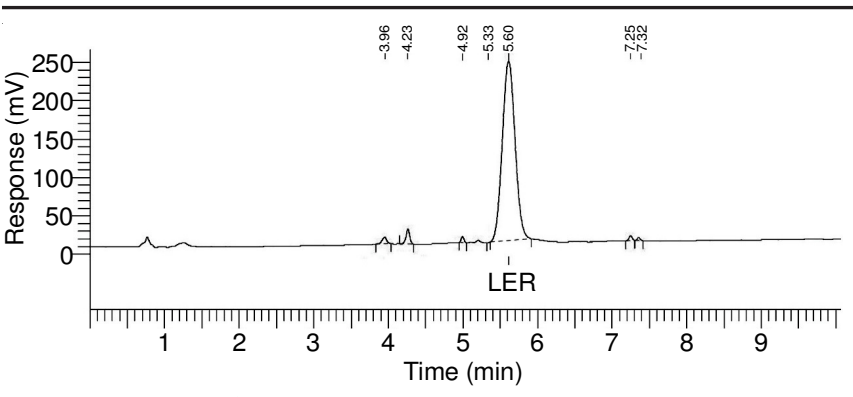

Fig. 15. Chromatogram of thermal degradation

TABLE-11

FORCE DEGRADATION DATA FOR LERCANIDIPINE HYDROCHLORIDE AT DIFFERENT CONDITIONS

\begin{tabular}{lcc}
\hline \multicolumn{1}{c}{ Degradation } & Conditions & Degradation (\%) \\
\hline Acid degradation & $1 \mathrm{~N} \mathrm{HCl}, 80^{\circ} \mathrm{C}, 1 \mathrm{~h}$ & 10.44 \\
Base degradation & $1 \mathrm{~N} \mathrm{NaOH}, 80{ }^{\circ} \mathrm{C}, 1 \mathrm{~h}$ & 8.46 \\
Hydrogen peroxide & $10 \% \mathrm{H}_{2} \mathrm{O}_{2}, 80^{\circ} \mathrm{C}, 1 \mathrm{~h}$ & 14.68 \\
induced degradation & & \\
Thermal degradation & $105^{\circ} \mathrm{C}, 24 \mathrm{~h}$ & 18.34 \\
\hline
\end{tabular}

Flow rate impacts HPLC system pressure, chromatographic quality, and analysis time. Therefore, it is necessary to choose an optimum pump flow rate. A higher than usual flow rate may adversely affect the quality of the chromatography not giving the analyte sufficient time to interact with the stationary phase. A lower than usual flow rate may unnecessarily increase retention time resulting in longer time of analysis.

Validation of the method: The method developed for lercanidipine hydrochloride was validated for analytical performance parameters such as linearity, accuracy, precision, specificity and quantification limits as per the ICH guidelines. The method was found to be linear with $\mathrm{r}^{2}=0.9995$, confirming the linear relationship between the concentration of the drug and the area under the curve.

The ruggedness/robustness testing of the method with deliberate alterations in parameters, like, composition of the mobile phase, mobile phase flow rate, injection volume, column temperature and detector wavelength, resulted in acceptable recoveries of lercanidipine hydrochloride, i.e. more than $97 \%$. No significant difference was found in the parameters of chromatographic separation (retention time, resolution and number of plates) on varying the operational parameters.

\section{Conclusion}

Accurate, precise and robust analytical RP-HPLC method for lercanidipine hydrochloride was developed using quality by design (QbD) approach on a Perkin Elmer HPLC system with Total Chrome navigator software for chromatography data system and Fusion AE method development software. The column/ solvent screening (Phase 1) and optimization (Phase 2) of the critical parameters of the HPLC like column, mobile phase, $\mathrm{pH}$, pump flow rate and sample concentration were performed using Fusion AE method development software and optimized the RP-HPLC chromatographic method for separation of lercanidipine hydrochloride. The developed RP-HPLC method was validated as per ICH guidelines Q2 (R1) in terms of precision, linearity, robustness, specificity and accuracy. All the validated parameters were found within acceptance criteria as per guidelines. The validated method is specific, linear, precise, accurate, robust and rugged for determination of lercanidipine hydrochloride. The proposed validated method was employed for forced degradation studies of lercanidipine hydrochloride.

\section{REFERENCES}

1. J.M. Juran, Juran on Quality by Design-The New Steps for Planning Quality into Goods and Services, McGraw-Hill, NY, USA, edn 5, pp. 1-21 (1992).

2. ICH Harmonised Tripartite Guideline, Pharmaceutical Development Q8 (R2) Current Step 4 (2009).

3. K.M. Younes and E.F. El-Kady, Int. J. Anal Bioanal Chem., 3, 169 (2013).

4. I. Popovic, D. Ivanovic, M. Medenica, A. Malenovic and B. Jancic, Chromatographia, 67, 449 (2008); https://doi.org/10.1365/s10337-008-0536-3.

5. A. Alvarez-Lueje, S. Pujol, J.A. Squella and L.J. Nunez-Vergara, J. Pharm. Biomed. Anal., 31, 1 (2003); https://doi.org/10.1016/S0731-7085(02)00601-5.

6. T.M. Sastry and R. Ramkrishna, Indian J. Chem. Technol., 16, 431 (2009).

7. S.C. Sweetman, Martindale: The Complete Drug Reference, Pharmaceutical Press, London, England, UK, edn 37 (2011).

8. N.V. Pasumarthy, A.V. Gopal and S.V.N. Hemakumar Padma, Asian J. Chem., 20, 630 (2008).

9. A.B. Baranda, R.M. Jimenez and R.M. Alonso, J. Chromatogr. A, 1031, 275 (2004); https://doi.org/10.1016/j.chroma.2003.11.019.

10. T. Christians, D. Diewald, C. Wessler, Y. Otte, J. Lehmann and U. Holzgrabe, J. Chromatogr. A, 853, 2151 (1999); https://doi.org/10.1016/S0021-9673(99)00566-X.

11. T. Christians and U. Holzgrabe, Electrophoresis, 21, 3609 (2000); https://doi.org/10.1002/1522-2683(200011)21:17<3609::AIDELPS3609>3.0.CO;2-0.

12. M. Barchielli, E. Dolfini, P. Farina, B. Leoni, G. Targa, V. Vinaccia and A. Tajana, J. Cardiovascul. Pharmacol., 29(Suppl. 2), S1 (1997).

13. ICH Harmonised Tripartite Guideline, Stability Testing of New Drug Substances and Products, Q1a (R2) Current Step 4 (2003).

14. J. Fiori, R. Gotti, C. Bertucci and V. Cavrini, J. Pharm. Biomed. Anal., 41, 176 (2006); https://doi.org/10.1016/j.jpba.2005.11.018.

15. A. Albini and E. Fasani, Photochemistry of Drugs: An Overview and Practical Problems, In: Drugs: Photochemistry and Photostability, Royal Society of Chemistry, pp. 1-73 (1998).

16. I.I. Salem, J. Idrees, J.I. Al Tamimi and P. Farina, J. Chromatogr. B, 803, 201 (2004); https://doi.org/10.1016/j.jchromb.2003.12.019.

17. ICH Harmonized Tripartite Guideline, Validation of Analytical Procedures: Text and Methodology, Q2 (R1) November (2005).

18. L.M. Bang, T.M. Chapman and K.L. Goa, Drugs, 63, 2449 (2003). 